\title{
Factors Affecting Motivation and Retention of Village Health Workers and Recommended Strategies: A Systematic Review from 11 Developing Countries
}

Dolley Tshering, Phudit Tejativaddhana, David Briggs, Neyzang Wangmo

Dolley Tshering - Ministry of Health of Bhutan - Department of Public Health, Ministry of Health District Health Sector, Trongsa Ministry of Health Thimphu 11001 Bhutan

Phudit Tejativaddhana - College of Health Systems Management, Naresuan University - College of Health Systems Management (CHSM), Phitsanulok, Phitsanulok, Thailand

David Briggs - College of Health Systems Management, Naresuan University - College of Health Systems

Management (CHSM), Phitsanulok, Phitsanulok, Thailand

Neyzang Wangmo - Khesar Gyalpo University of Medical Sciences of Bhutan - Medical Education Centre for Research Innovation and Training (MECRIT), Thimphu, Thimphu, Bhutan

Correspondence: phuditt@nu.ac.th

\section{Abstract}

Introduction: Motivation and retention of village health workers (VHWs) are crucial for the continuity, sustainability, and success of health programs. VHWs are the first point of contact for rural communities, providing health services to improve access and health coverage which, for a variety of logistical reasons, cannot be reached by the district health care system. Thus VHWs are critical for ultimately ensuring universal health coverage. However, systematic review revealed that there are numerous factors that affects their motivation and retention, leading to high dropout rates and hampering the delivery of health services to the community. This review intends to examine contextual factors affecting motivation and retention of VHWs in their roles and identify recommendations and strategies to motivate and retain them in the systems.

Method: Five electronic databases and two search engines were accessed. Nineteen studies met the inclusion criteria for the final review. An in-depth reading of all the articles was undertaken to gather and compile the relevant themes. Content analysis was done based on the list of specific categories that are relevant to motivation and retention.

Result: Findings from the systematic review revealed different levels of factor affecting motivation and retention of village health workers. It was finally contextualized and categorized into four main domains such as individual, family, social or community and organizational or systems levels. Financial incentives under the organizational factors was highlighted for the demotivation and the discontentment for the VHWs.

Conclusion Financial factors under the organization were often key in the studies reviewed. However, there were also many other factors, sometimes surprising or unintuitive, influencing the motivation and retention of village health workers.

Keywords: motivation, retention, village/community health worker, developing countries, factors 


\section{INTRODUCTION}

\subsection{Background}

Globally there is an acute shortage of health workers, especially in developing countries, and task shifting to village health workers (VHWs) is one way to address the human resource shortages. [1,2] Given the growing importance of VHWs, there is also growing concern about motivating and retaining them. [3] VHWs are local health-care workers who are selected by the community to look after the health and well-being of the community and who are trained in selected basic health topics. $[4,5]$ They are often interchangeably referred to as community health workers (Uganda), village health volunteers (Thailand), bare foot doctors (China), lay health workers (South Africa) and so on. [6,7] In Bhutan, it is termed as VHW. [5] They are essential for promoting and achieving Primary Health Care (PHC) at the community level bridging the gap between the health system and the communities. [5,8]

This crisis of human resources for healthcare, which extends to VHWs, has been considered one of many underlying factors hindering the performance of effective health service delivery, particularly in developing countries. $[7,9]$ VHWs have a vital role to play in achieving Sustainable Development Goals (SDG) and reaching Universal Health Coverage (UHC). $[10,11]$ since $U H C$ is one of the important objectives and renewed focus of SDG to attain equitable and sustainable health outcomes and improve the well-being of individuals, families and communities. [12,13]

\subsection{Purposes of the review}

Volunteer-based programs are often hampered due to high dropout rates, which increases training costs due to the resulting requirement to constantly provide replacement workers to sustain the program.
[14] The motivation and retention of VHWs have become critical for the sustainability of health programs, as a high dropout rate not only significantly impedes the delivery of health service but delays achievement of Universal Health Coverage. [7]

Despite providing various incentives, for example allowances or other, non-financial benefits that are feasible and affordable, such as recognition and appreciation through training, study tours, or awards, most of the countries continue to experience challenges with motivation and retention, as evidenced by persistently high dropout rates. $[5,6,9,15]$

Studies had identified a number of significant factors that increase motivation [16] as well as demotivating factors that lead to loss of VHWs. $[2,17]$ Developing and implementing effective strategies for retention of VHWs in the community will speed up positive health outcomes and reduce disease burden. $[18,19]$ Since a significant amount of research now exists from widely varying sources, a comprehensive literature review will help in identifying the contextual factors most affecting motivation and retention of VHWs in the health system.

\section{METHODS}

Articles related to VHWs from developing countries were sought out using five electronic databases: Scopus, Web of Science, PubMed, Science Direct and Springer Link; and two search engines: Google Scholar and NU Library One Search; searching for the keywords "village/community health worker", motivation, retention, and "developing countries". The search generated 246 relevant articles (49 from the web of science, 15 from Scopus, 13 from ScienceDirect, 12 from PubMed, 15 from Springer Link, 21 from Google scholar, and 121 from NU Library One 
Search). The inclusion criteria used were peerreviewed articles published in developing countries related to the review topic from the year 1990 to April 2017. In this way, 19 articles were selected as shown in Figure 1. Developing countries include Thailand, Nepal, India,
Bangladesh, Kenya, South Africa, Uganda, Tanzania, Zimbia, Liberia and Bhutan based on the availability of study conducted on the review topic.

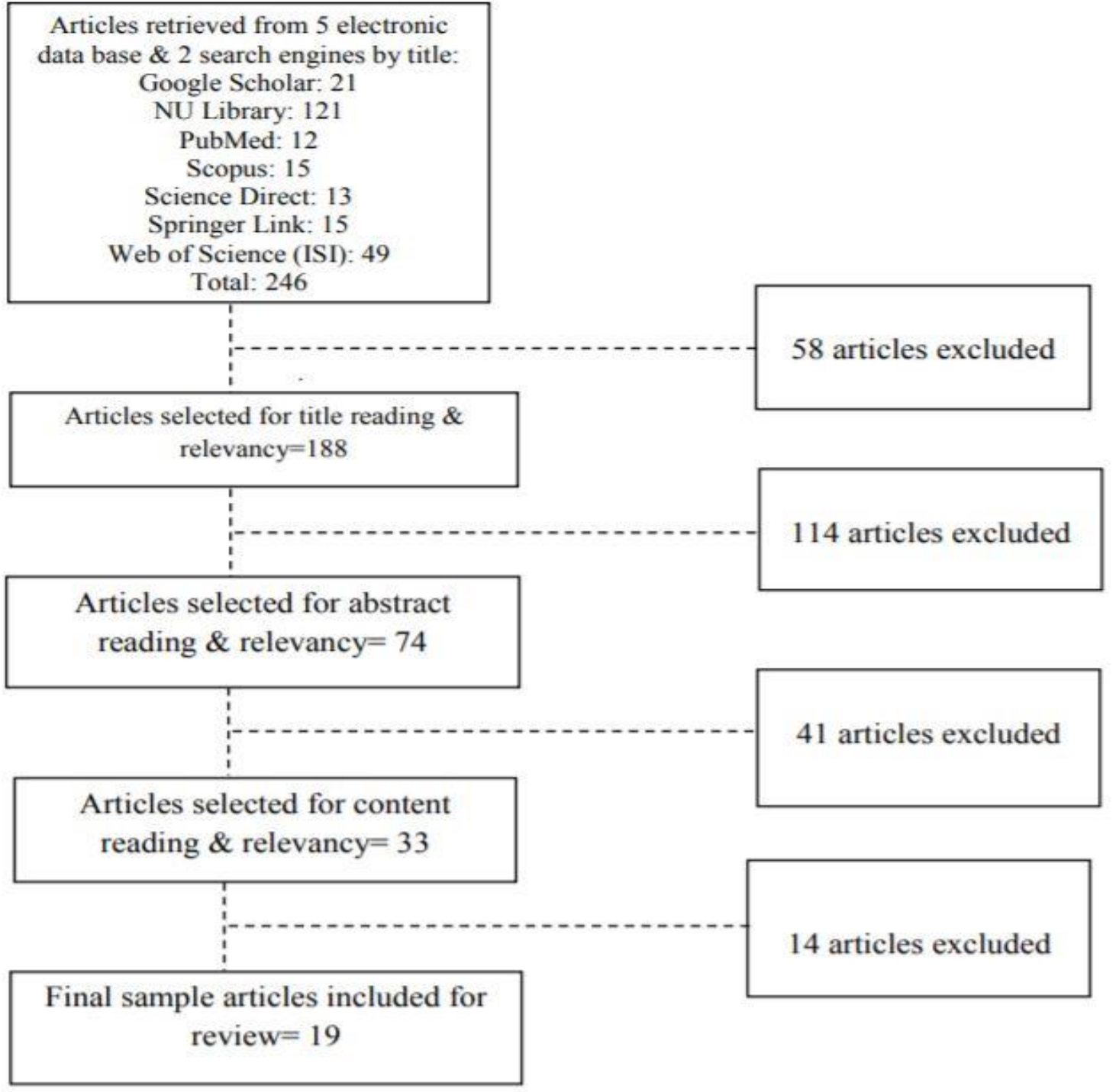

Figure 1: Flow chart of search strategy

Source: Developed for this review

Meta-synthesis was used to integrate, evaluate and interpret the findings from many qualitative studies in order to identify the common core element and theme of the factors affecting motivation and retention of VHWs. Following the detailed reading of the articles, the Preview, Question, Read and Summarize (PQRS) concept [20] was applied to 
identify the themes. Content analysis was done to synthesize the main categories of contextual factors affecting motivation and retention. These factors were then grouped under four domains: individual, family, social or community and organization or system factors.

\section{RESULTS}

This systematic review found out the range of factors which are conceptualized and categorized under four main domains as showed in the conceptual framework in figure 2. The detail factors are listed below.

\subsection{Individual factors}

\subsubsection{Socio-demographic characteristics} The socio-demographic characteristics such as age and education of the VHWs affects the motivation and performance of village health workers as per studies conducted in Busia District in Kenya, Morogoro Region in Tanzania and Kibwezi district, Kenya in 2014. [21,22] Similarly, studies in Bangladesh and Nepal concluded that personal and family factors contributed to the motivation and the retention of VHWs in the system. $[17,23,24]$ Personal factors such as the desire to improve and develop one's personal skills were stated as the source of motivation for VHWs. $[17,23]$ Moreover, it was found that they wanted to gain knowledge about health in order to look after the health of their own family. $[3,25,26]$ However, other studies found that due to lack of time to do personal work. [27]

\subsubsection{Job opportunities}

A study conducted in Bangladesh in 2010 found that the factor that most often led VHWs to leave their job was a better job opportunity to work for the government, such as opportunities to become primary school teachers and other supervisory positions. [17]

\subsection{Family factors}

The family factor is one of the most important factors to motivate and encourage VHWs to work for the people. However, lack of support from the family members becomes a hindrance for them to continue to work further and much better. Family factor includes marriage and childbirth, availability of workforce and support and cooperation from the family members as stated below.

\subsubsection{Marriage and childbirth}

The main reason for women to leave from their work as VHWs was due to family reasons since they had to look after their children and take care of household chores after getting married. [17]; [28] VHWs also had difficulties with work-related travel, for example traveling at odd hours outside of the already long hours of work, which was seen to be inappropriate for female VHWs by their husbands. [29]; [17] Female VHWs also experienced being blamed by family members and neighbors for neglecting their children. [30]

\subsubsection{Workforce}

Although, studies reported that they have a willingness to serve as VHWs but due to the shortage of people to do the household chores were seen as demotivating factor. [28] Similarly, having to compromise their personal work and need to shoulder family responsibilities since there was no one to look after the household matters affected retention of VHWs in the system. $[9,28]$

\subsubsection{Family support}

Studies conducted in Bangladesh (2010), Tanzania (2013) and India (2016) revealed that the support and encouragement from family and neighbours motivated people to become VHWs. $[2,17,23]$ However, due to insufficient remuneration to look after their family 
especially for female VHWs, were the main reasons for family disapproval. $[17,28,29,31]$

\subsection{Social factors \\ 3.3.1 Social support}

The study conducted by Takasug and Glenton found that the that social support received from the community were the important factors motivating the performance of VHWs [16] and in building a sense of obligation to their community. [24] Studies conducted by different authors found that the social support was significant for the motivation and retention of VHWs to work harder along with the combined efforts of the community people. $[7,16,18,23,25,28]$

\subsubsection{Social recognition}

Personal value and recognition through words of encouragement and psychological and emotional support were seen as powerful influencing factors for improving the health of the community by VHWs. $[3,17,25,26]$ studies also confirmed that the community recognition play a significant role for the VHW's to performance their work better and motivation to achieve community goals. $[3,17,25,26]$

\subsection{Organizational factors}

Incentives (both financial and non-financial) were the key drivers motivating the health workforce with regards to VHWs in Bhutan [32] and other countries. [33] Various job benefits influenced the motivation and retention of VHWs [16] and further improved work performance. [23]

\subsubsection{Financial incentives}

Financial incentives were the main factor linked to retention of VHWs. [28] The same study found that VHWs who joined with the expectation of benefits were almost twice as likely to remain in the system. The study by
Takasugi \& Lee emphasized the importance of financial incentives to enable VHWs to support their families and pointed out that occasionally they needed to spend their own money for their work, for example, costs for transportation and phone calls without compensation. [16] The study conducted in Bangladesh also supported the finding that VHWs discontinued their service because of irregular salary. [31] Five other studies highlighted the lack of financial benefit either in cash or kind as one of the demotivating factors but it was also argued that that incentive could alter the essence of volunteerism and hamper the "service mind" tradition. [15]

\subsubsection{Non-financial benefits}

Community approval and social prestige were significant non-financial factors linked with retention of VHWs. [28] Non-financial incentives also included shirts and badges for their identification both in hospital and community settings and personal safety in the community. [16] The indirect benefits such as preferential services when they and their immediate family members visit the health facility were also valued and motivating. [16]

\subsubsection{Recruitment and selection}

Recruiting and selecting the most suitable individuals was seen as a crucial factor. [34] The study in Western Kenya that carried out focus group discussions and in-depth interviews with VHWs discovered that there was a lack of clear selection criteria, which resulted in some inappropriate candidates becoming VHWs and later ending up as dropouts. [29] The reason behind the selection of unsuitable candidates to be trained as VHWs was found to be that $91 \%$ of VHWs were chosen by the community, $6 \%$ by the community leaders and $3 \%$ by the rural health center staffs. [35] 


\subsubsection{Support and supervision}

Besides not involving input from VHWs during planning as a demotivating factor, [30] it was also found that poor support and supervision from the organizational level for the betterment of the health delivery services discouraged the VHWs. [2,35] It was also mentioned that VHWs were not acknowledged or recognized by the organization for the work they did and not fully supported after the initial training was over. [36] Moreover, job burnout and poor career development opportunities [2], as well as inadequate support by the organization to get them a fair monetary return for the time and labour invested, were felt as demotivating factors. [27]

\subsubsection{Working environment}

Generally, the working environment and social obligations were seen as important elements in people's decision to become VHWs but it was mentioned that they were having discomfort with the night travel and work assignments during holidays. [17] It was also concluded that night travel and other unusual duties, particularly in rainy season, as well as a lack of transportation were particular problems since most of the health facilities are located far from their villages. $[15,16,37]$

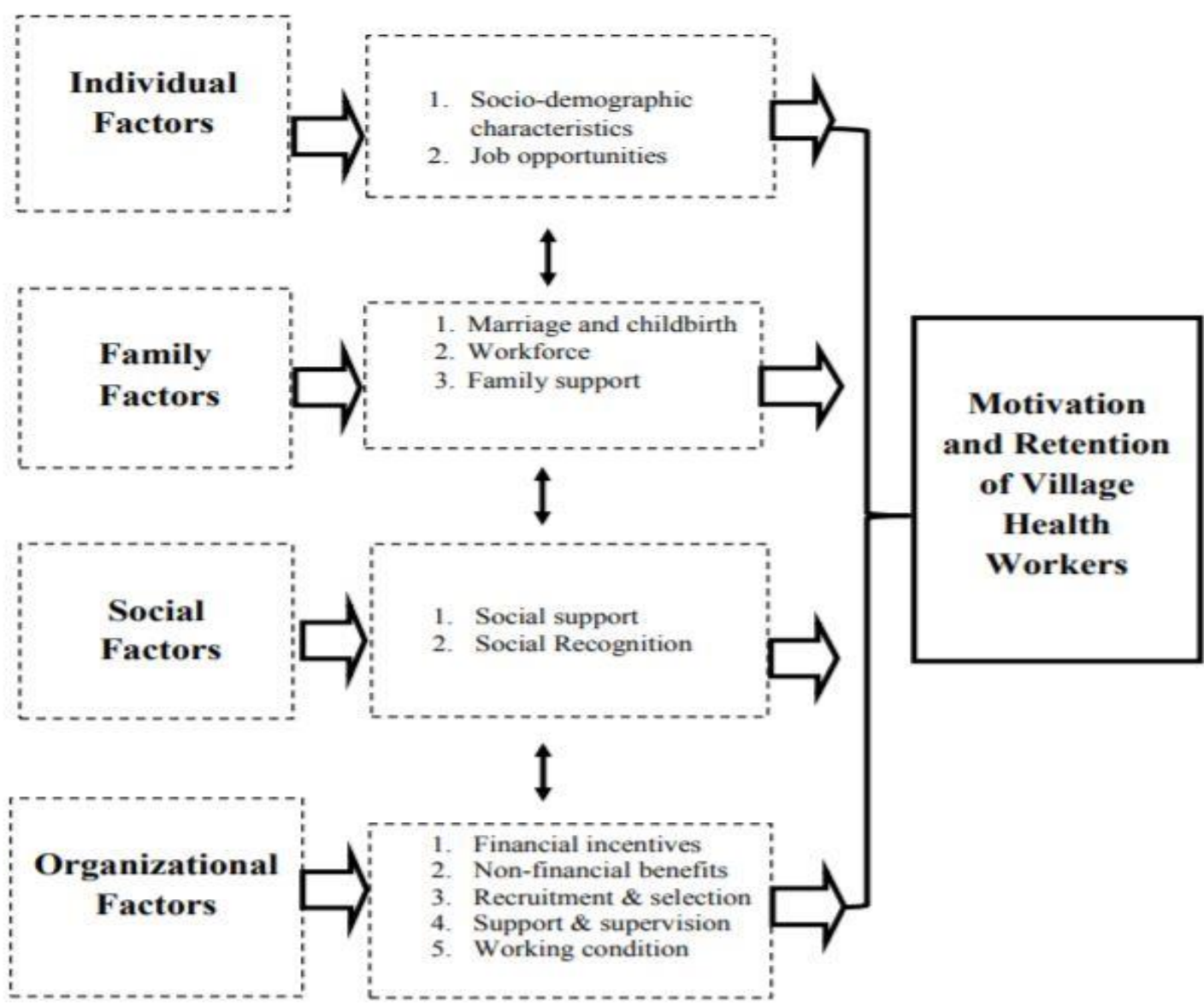

Figure.2: Conceptual framework

Source: Developed for this study 


\section{RECOMMENDED STRATEGIES}

A universal point in the discussion of recommended strategies was the importance of financial incentives for the motivation of the VHW, as these contribute significantly to job satisfaction and work performance. [16] Restructuring and expansion of existing financial incentives was recommended in order to strengthen the commitment and participation of VHWs, which in turn can benefit programs directly, as well as provide value to the health system. [28]

However, a few studies suggested that it may not be necessary to provide a generic set of incentives for the resource-limited settings. Instead, program managers and policy makers should give a high level of attention to the specific context of each VHW's work. [31] A sustainable model for VHWs, where they can enjoy some financial benefits out of their essentially voluntary work and an elaborate mechanism of non-monetary incentives based on performance, should be practiced to inspire, appreciate and recognize their works. [27] A framework for the decision-making process and the sustainable model of VHW were proposed, adopting simple strategies of retention as community-based sustainable health interventions to accelerate the positive health outcomes. [18]

Having a framework for a decision-making process provides an opportunity for the VHW to negotiate to increase the benefits and/or reduce out of pocket costs to the VHWs. [15] A sustainable model for VHWs particularly emphasizes factors other than financial incentives, such as community acceptance and approval, family support, cooperation, appreciation and recognition by the supervisors and the community. [27]

The application of what is called a 'friction cost approach' can be useful for measuring the impact of VHW dropouts in relation to service interruption to the community. This method would help to estimate the indirect costs due to productivity loss. The friction period is the time until another VHW has replaced the individual who left the program. [18]

Finally, additional future research has been recommended and, such research is felt necessary to better understand nuances regarding intrinsic vs. extrinsic factors that motivate people to enlist as a VHW. Additional research would also be useful to study in greater detail the relationship between job satisfaction and performance. [22]

\section{DISCUSSION}

In many developing countries, VHWs not only play an important role in the delivery of healthcare services in the community [38] but also serve as agents of change in promoting healthy behaviors and reducing health inequities, all at a relatively low cost. [3] High dropout rates of VHWs adversely impact the sustainability of health equity, especially in the unreached pockets of the population, which are also important in reducing disease burden in the community. [39]

Financial incentives were described as the main factor linked to retention of VHWs in the system. $[17,28]$ However, no one has claimed that financial incentives are the sole motivating factor. [27] Rather, VHWs can be motivated and retained by factors other than financial remuneration as well. [25] The studies did not agree unanimously that financial incentives posed a risk of changing the essence and mindset of volunteerism and further eroding the VHWs' attitude towards service. [15]

Among the numerous factors affecting the motivation and retention of VHWs at the individual level, the most significant factors were identified as marriage and childbirth, 
better job opportunities, shortage of labour force at home and finally opposition from family members. Social factors play a role as well. [17] Other potential threats to the retention of VHWs in the system included lack of social support or lack of recognition as well as unconducive working environments because of the nature of the job. [16]

Further, lack of support and supervision at the organizational level were concerning factors. $[27,29]$ Job burnout, personal health problems, job security and limited career development opportunities were also found to be demotivating factors [2,36], as were heavy workloads, travel at night especially to work far from the home area, and inadequate monetary return against the time and labour invested. $[17,30]$

The dropout of VHWs impacted not only the cost incurred for new recruitment and training but also the interruption of service to the community. [18] Thus, improved retention of the VHWs would create a positive health impact, contributing to the reduction of the burden of illness and helping the health services reach all the population.

A mixture of research designs was used in the studies. However, the majority were qualitative studies. All the data was sampled from village health workers although they were working in various geographical areas.

Attention must be given to supporting the personal growth of VHWs. For example, they should be provided with appropriate economic support, communication, and coordination with the communities they serve and other stakeholders. The VHW's capacity, both their knowledge and skills, should be nurtured and developed. This will encourage them to continue in their work, and thereby expand the VHW program, sustaining momentum and strengthening the health systems.

\section{CONCLUSION}

This meta-synthesis of evidence showed the contextual factors affecting motivation and retention of VHWs in developing countries. It was determined that the factors were not confined only to financial incentives but also included other factors as well. Attention must also be given to factors at the individual, family, community and the organizational levels. These factors had great potential to impact the motivation and further retention of VHWs in the system. The findings gathered from these numerous studies conducted in different countries help both to understand the factors affecting motivation and retention of VHWs and to devise appropriate strategies for effective policy interventions. This information is useful for addressing existing problems of motivation and retention of VHWs in health systems and further improving health service delivery.

\section{LIMITATIONS}

The initial search retrieved a limit of 246 articles based on relevancy to the review topic, and from those a limit of 19 articles qualified for inclusion in the final sample. Since the search was in English, studies conducted in other languages may have been missed and overlooked. The review had a scope of eleven developing countries that had conducted research on the topic. Moreover, this was a narrative review and therefore, the content may not be of the most extreme depth possible. 
Declarations:

Ethical approval and consent to participate: Not applicable

Consent for publication: All authors unanimously agreed and consented to send the manuscript to Asia Pacific Journal of Health Management for publication.

Availability of data and materials: All data generated or analyzed during this review were included from the published articles listed in the references.

Competing interests: No competing interest

Authors' contribution: The author and co-authors read and approved the final manuscript

Acknowledgment: The author (s) would like to thank Mr. Paul Freund and Mr. Kevin Mark of Naresuan University, Writing Editors for English Language for checking and editing for correct English usage and clarity.

Funding: Not applicable

\section{Reference}

1. WHO. Working Together For Health, The World Health Report. Vol. 19. Geneva, Switzerland: World Health Organization; 2006. 237 p.

2. Dambisya MY, Tripathy JP, Goel S, Kumar AM V, Bangdiwala SI, Fonn S, et al. Measuring and understanding motivation among community health workers in rural health facilities in India-a mixed method study. BMC Health Serv Res. 2016;32(44):366.

3. Owek C, Abong'o B, Oyugi H, Oteku J, Kaseje D, Muruka $C$, et al. Motivational Factors that Influence Retention of Community Health Workers in a Kenyan District. Public Heal Res [Internet]. 2013;3(5):109-15. Available from:

http://article.sapub.org/pdf/10.5923.j.phr.20130305.01. pdf

4. WHO. The state of the evidence on programmes, activities, costs and impact on health outcomes of using CHWs, Geneva. 2007; (January).

5. Department of Public Health. Village Health Workers Programme Strategy and Action Plan (2017-2023). Thimphu, Bhutan: Ministry of Health; 2017. i-xviii. 6. UNICEF. What Works for Children in South Asia: Community Health Workers. Kathmandu, Nepal: United Nations Children's Fund; 2004. 1-36 p.

7. WHO. Global Experience of Community Health Workers for Delivery of Health Related Millennium Development Goals: 391 p.

8. Department of Public Health. Comprehensive Review of the Village Health Workers Program: Primary Health Care Initiative in Bhutan. Thimphu, Bhutan: Village Health Worker Program, Ministry of Health; 2012. 1-56. 9. Alam K, Tasneem S, Oliveras E. Performance of female volunteer community health workers in Dhaka urban slums. Soc Sci Med [Internet]. 2012;75(3):511-5. Available from:

http://dx.doi.org/10.1016/j.socscimed.2012.03.039
10. Maher D, Cometto G. Research on community-based health workers is needed to achieve the sustainable development goals. Bull World Health Organ. 2016;94(11):786.

11. Dahn B, Tamire Woldemariam A, Perry H, Akiko M, Al E. Strengthening Primary Health Care through Community Health Workers: Investment Case and Financing. 2015;(July).

12. WHO. Arguing for Universal Health Coverage (UHC). Geneva, Switzerland: World Health Organization; 2013. 1-40.

13. WHO. Global Strategy on Human Resources for Health:Workforce 2030. Geneva, Switzerland: World Health Organization; 2016. 1-64 p.

14. Haines A, Sanders D, Lehmann U. Achieving child survival goals: potential contribution of community health workers. Lancet. 2007;369(9579):2121-31.

15. Kowitt SD. Community Health Workers as Agents of Health Promotion: Analyzing Thailand's Village Health Volunteer Program. 2015;780-8.

16. Takasugi T, Lee ACK. Why do community health workers volunteer? A qualitative study in Kenya. Public Health [Internet]. 2012;126(10):839-45. Available from: http://dx.doi.org/10.1016/j.puhe.2012.06.005 17. Rahman SM, Ali NA, Jennings. Factors affecting recruitment and retention of community health workers in a newborn care intervention in Bangladesh. Hum Resour Health. 2010;8(1):12.

18. Alam K, Khan JAM, Walker DG. Impact of dropout of female volunteer community health workers: An exploration in Dhaka urban slums. BMC Health Serv Res. 2012; $12: 260$

19. Kuule Y, Dobson AE, Woldeyohannes D, Zolfo M, Najjemba R, Edwin BMR, et al. Community Health Volunteers in Primary Healthcare in Rural Uganda: Factors Influencing Performance. Front Public Heal [Internet]. 2017;5(March):1-8. Available from: 
http://journal.frontiersin.org/article/10.3389/fpubh.201 7.00062/full

20. Marlini C. Developing PQRST (Preview, Question, Read , Summarize And Test ) Strategy-Based Intensive Reading Institutional Materials For The Students In Grade IV OF Elementary. 2008;

21. Crispin N, Wamae A, Ndirangu M, Wamalwa D, Wangalwa G, Watako P, et al. Effects of Selected SocioDemographic Characteristics of Community Health Workers on Performance of Home Visits during Pregnancy: A Cross-Sectional Study in Busia District, Kenya. Glob J Health Sci [Internet]. 2012;4(5):78-90. Available from:

http://www.ccsenet.org/journal/index.php/gjhs/article/ view/17085

22. Mpembeni RNM, Bhatnagar $A$, Lefevre $A$, Chitama $D$, Urassa DP, Kilewo $C$, et al. Motivation and satisfaction among community health workers in Morogoro Region, Tanzania:nuanced needs and varied ambitions. 2015;110.

23. Greenspan JA, McMahon SA, Chebet JJ. Sources of community health worker motivation: a qualitative study in Morogoro Region, Tanzania. Hum Resour Health [Internet]. 2013;11(1):52. Available from: http://humanresources-

health.biomedcentral.com/articles/10.1186/1478-4491-

11-52

24. Glenton C, Scheel IB, Pradhan S, Lewin S, Hodgins S, Shrestha $V$. The female community health volunteer programme in Nepal: Decision makers' perceptions of volunteerism, payment and other incentives. Soc Sci Med [Internet]. 2010;70(12):1920-7. Available from: http://dx.doi.org/10.1016/j.socscimed.2010.02.034 25. Singh D, Cumming R, Mohajer N, Negin J. Motivation of Community Health Volunteers in rural Uganda: the interconnectedness of knowledge, relationship and action. Public Health. 2016; 136:166-71.

26. Rosenberg E. Motivating Factors Contributing to Retention of Community Health Workers in Rural Liberia: A Qualitative Study. Ann Glob Heal [Internet]. 2017;83(1):135-6. Available from:

http://linkinghub.elsevier.com/retrieve/pii/S221499961 7303648

27. Ahmed SM. Taking healthcare where the community is: the story of the Shasthya Sebikas of BRAC. Asia-Pacific Action Alliance Hum Resour Heal Annu Conf. 2007;

$\mathrm{V}(1): 1-15$.

28. Alam K, Tasneem S, Oliveras E. Retention of female volunteer community health workers in Dhaka urban slums: A case-control study. Health Policy Plan.

2012;27(6):477-86.

29. Omondi C, Nyamongo IK, Aagaard-hansen J. Staff attrition among community health workers in homebased care programmes for people living with HIV and AIDS in western Kenya. Health Policy (New York). 2010; 97:232-7.

30. Tripathy JP, Goel S, Kumar AM V. Measuring and understanding motivation among community health workers in rural health facilities in India-a mixed method study. BMC Health Serv Res [Internet]. 2016;16(a):366. Available from:

http://www.ncbi.nlm.nih.gov/pubmed/27507034\%5Cnh ttp://www.pubmedcentral.nih.gov/articlerender.fcgi?art id=PMC4977615

31. Alam K, Oliveras E. Retention of female volunteer community health workers in Dhaka urban slums: a prospective cohort study. Hum Resour Health. 2014;111.

32. Ministry of Health. Human Resource for Health Country Profile. Thimphu, Bhutan: Ministry of Health; 2014. 1-53 p.

33. WHO. Global Experience of Community Health Workers for Delivery of Health Related Millennium Development Goals. Community Health (Bristol). 2010;1-377.

34. Jaskiewicz W, Deussom R. Recruitment of Community Health Workers. 2013;(September). 35. Stekelenburg J, Kyanamina SS, Wolffers I. Poor performance of community health workers in Kalabo District, Zambia. Health Policy (New York). 2003;65(2):109-18.

36 . Kironde $\mathrm{S}$, Klaasen $\mathrm{S}$. What motivates lay volunteers in high burden but resource-limited tuberculosis control programmes? Perceptions from the Northern Cape province, South Africa. Int J Tuberc Lung Dis. 2002;6(July 2001):104-10.

37. Kauffman KS, Myers DH. The changing role of village health volunteers in northeast Thailand: an ethnographic field study. Int I Nurs Stud. 1997;34(4):249-55.

38. Kok MC, Kane SS, Tulloch O, Ormel H, Theobald S, Dieleman $\mathrm{M}$, et al. How does context influence performance of community health workers in low- and middle-income countries? Evidence from the literature. Heal Res Policy Syst [Internet]. 2015;13(1):13. Available from: http://www.health-policysystems.com/content/pdf/s12961-015-00013.pdf\%5Cnhttp://www.health-policysystems.com/content/13/1/13

39. Dieleman M, Harnmeijer JW. Improving health worker performance: in search of promising practices. 2006;(September). 